\title{
Health Risk Associated with Pesticide Contamination of Fish from the Densu River Basin in Ghana
}

\author{
Joseph R. Fianko ${ }^{1,4, *}$, Augustine Donkor ${ }^{2}$, Samuel T. Lowor ${ }^{3}$, Paul O. Yeboah ${ }^{4}$, Eric T. Glover ${ }^{1}$, \\ Theodosia Adom ${ }^{5}$, Augustine Faanu' ${ }^{6}$
}

${ }^{1}$ NNRI/GAEC, Legon, Accra; ${ }^{2}$ Department of Chemistry, University of Ghana, Legon, Accra; ${ }^{3}$ Cocoa Research Institute of Ghana, Akim Tafo; ${ }^{4}$ School of Nuclear and Allied Sciences, University of Ghana, Legon, Accra; ${ }^{5}$ BNARI/GAEC, Legon, Accra; ${ }^{6}$ RPI/ GAEC, Legon.

Email:jrfianko@yahoo.com

Received August 19 $9^{\text {th }}, 2010$; revised October 18 $8^{\text {th }}, 2010$; accepted December $21^{\text {st }}, 2010$.

\begin{abstract}
The Densu River Basin constitutes one of the largest agricultural areas in Ghana. The practice of using pesticides such as organochlorines, organophosphates, carbamates, pyrethroids and several others in agriculture and public health programs has raised concerns about potentially adverse effects on human health and the environment. In this study, a field survey was conducted to assess farmers' knowledge of safe handling and use of pesticides. Residues of pesticides in fish samples as well as the potential health risk associated with exposure to these pesticides were also evaluated. Data obtained from the field survey indicate that a very high proportion of farmers are at high risk of pesticide poisoning from occupational exposure. More than $90 \%$ of farm workers do not practice safety precaution during pesticide formulation and application leading to considerable prevalence of pesticide related illness in this agricultural community. Pesticide residues in fish samples varied greatly; from $0.10 \mu \mathrm{g} \cdot \mathrm{Kg}^{-1}$ to $30.90 \mu \mathrm{g} \cdot \mathrm{Kg}^{-1}$, consumption of fish and fisheries product from the basin was no zero risk. The estimated dose for aldrin, methoxychlor, $\gamma$-chlordane, endrin aldehyde, endrin ketone, endrin, $p^{\prime} p^{\prime}-D D T$ and $\delta$ - HCH do not pose a direct hazard to human health, although present in fish samples since the values were lower than toxic thresholds as well as reference dose. However, $\gamma$-HCH, heptachlor, $\alpha$-endosulfan, endosulfan Sulphate, $p^{\prime} p^{\prime}-D D E$ and dieldrin levels exceeded the reference dose, indicating a great potential for systemic toxicity in children who are considered to be the most vulnerable population subgroup.
\end{abstract}

Keywords: Ghana, Pesticide Residue, Exposure, Health Risk, Densu

\section{Introduction}

One of the most negative consequences of industrial development in the world has been the use and disposal of pesticide that are potentially hazardous to human health. Severe health effects are associated with exposure to pesticides in food. Although the presence of trace levels of pesticides in food is considered as an indication that contamination has occurred, the risk of adverse health effects depends on their concentration, frequency of contact and duration of exposure. Contamination results in exposure to toxic substances for the resident populations leading to harmful health effects. Ingestion of pesticide in food has been linked with health conditions that are a major source of morbidity and mortality and increased risk of skin, bladder and lung cancer at very low concen- trations [1-3]. The use of pesticides has led to an increased production of food and fiber as well as profitability in agriculture. However, their use has also been associated with several concerns including the risks to human health, the death of farm animals and the alteration of the local environment $[4,5]$ particularly in countries where regulations are not strictly implemented and farmers' knowledge of safe handling procedures is inadequate.

All substances exert some degree of toxicity to various forms of life, depending on the exposure level of the substance. The risks of pesticide inputs to the environment also vary with the toxicological, physical and ecological properties of the pesticide. Fish and processed fish are major animal protein sources to human in Ghana. A number of pesticides have been identified as likely to cause disturbances to natural hormones in our bodies. 
Unfortunately, they are commonly found in food such as fish. Consumption of contaminated fish and fisheries products could therefore be a serious risk to human [1]. Excessive usage can have effects such as disruption of neurological cellular functions, acute and chronic neurotoxicity, tissue or organ damage, irritation and chemical burns [2]. The discovery of an association between subtle neurologic effects and low-level lead exposure in children as well as findings of developmental toxicity from low-level intra-uterine exposure of polychlorinated biphenyls has led many researchers to construct analogous hypothesis related to pesticides $[3,6]$. Recent reports on developmental neurotoxicity of the insecticide chlorpyrifos lend support to this area of investigation [6].

Pesticides are widely used in agriculture and sanitation for defense of pests in Ghana. Agriculture is a traditional economic activity in the Densu River Basin. With the intensification of agricultural production in Ghana, there has been an increase usage of pesticides; however, little attention is given to health hazards associated with their use. Procedures recommended for the safe handling of these pesticides have not been followed conscientiously. Repeated pesticide application may put farmers at risk with chemicals being dispersed, leaked or spilled and entering the human body either directly or indirectly. A higher proportion of pesticide poisoning and illness occurs in remote agricultural areas where there are inadequate occupational safety standards, insufficient enforcement of pesticide-related legislation, poor labeling of pesticide containers, illiteracy, inadequate protective clothing and washing facilities as well as user's lack of knowledge of pesticide hazards $[4,7]$.

The Densu river basin is primarily an agriculture area with intense pesticide usage. Pesticides are extensively used in the basin for pineapple, cocoa, vegetables, cereals and fruit productions as well the control of vector-borne diseases for public health. Economic activities in the basin also include fishing and industrial development. Fish from the basin serves as the major source of income for most of the inhabitants. Fish in the Densu basin also constitutes an important source of protein for the inhabitants in and around the basin as well as the entire country. Agricultural, domestic, municipal and industrial activities have impacted negatively on the basin since effluents and other storm water drains from these activities empty into the basin. Bioaccumulation and bio-concentration of pesticides in the fish species are capable of reaching toxic levels in the fish even when exposure is low [4].

Human exposure to pesticides through fish and fish products from the Densu River Basin may be excessive, especially through ground application of pesticides in cocoa, pineapple, cotton and vegetable farms; where compounds of high toxicity are often used but no studies have been done to assess the health risk associated with the contamination of fish from the basin. Studies in other parts of the country $[2,8-12]$ related several disease conditions such as headache, blurred vision, fever skin irritation, abdominal pains, cough, nausea and dizziness to pesticide poisoning. The Densu River basin has a long history of pesticide usage; consumption of fish and fish products from the basin is on the increase, however, there exists no amount of epidemiological data concerning the risk of farmers and consumers of fish from the basin. This study therefore seek to evaluate the potential health risk associated pesticide contamination of fish from the basin and to assess the knowledge, practices and attitudes regarding safe use of pesticides, toxicity awareness and symptoms among farmers in the Densu River basin.

\section{Materials and Method}

\subsection{Field Investigation}

A field survey was conducted in all communities within the Densu River Basin (Figure 1) between March and December 2007 during which a questionnaire was administered to a total of 200 farm heads, farmers and farm workers in the basin. The questionnaire focused on the assessment of knowledge, attitudes and practices of these farm workers regarding the safe use of pesticides, toxicity awareness and the identification of most prominent health related issues in the area. During the survey, fresh fish samples were purchased from the two major fishing communities (Nsawam and Weija) in the basin. The fish samples were bought when still alive, directly from the fishermen. The fish samples were immediately wrapped in aluminum foil, appropriately labeled, transported to the laboratory on ice and kept at $-20^{\circ} \mathrm{C}$ in a freezer prior to extraction.

\subsection{Sample Extraction}

The extraction of pesticides from fish samples was performed by solid dispersion method as described by the US Food and Drug Administration, [13] and Akerblom [14]. Two hundred grams of fish samples were homogenized in a stainless steel blender. About $25 \mathrm{~g}$ portion of the homogenized fish sample was grounded with $10 \mathrm{~g}$ sand and about $35 \mathrm{~g}$ of $\mathrm{Na}_{2} \mathrm{SO}_{4}$ (anhydrous) in a mortar to free-flowing powder. The powder was extracted in a flask by shaking successively with ethyl acetate (50, $3 \times$ $20 \mathrm{ml}$ ). The combined extract was filtered through a cotton wool and the solvent evaporated at $40^{\circ} \mathrm{C}$ with rotary evaporator to near dryness. The concentrate was recovered with $(3 \times 1.5 \mathrm{ml})$ portions of cyclohexane. The organic phase was then subjected to clean-up.

\subsection{Clean-Up of Sample Extracts}

Conditioned 8-ml C-18 solid phase extraction (SPE) car- 
tridges were used for the sample clean-up [15]. Each fish extract was percolated through the cartridges with a flow rate of approximately $5 \mathrm{ml} / \mathrm{min}$ under vacuum pump. The pesticides trapped in the cartridges were eluted with $6 \mathrm{ml}$ $(2 \times 3 \mathrm{ml})$ ethyl acetate. The sample extract was concentrated using the rotary evaporator aided with a water chiller to $2 \mathrm{ml}$ for $\mathrm{GC}$ analysis.

\subsection{Analysis of Pesticides}

Fish samples were analyzed in a gas chromatograph (Varian CP-3800 gas chromatograph) equipped with Ni-63 electron capture detector (ECD) and Flame ionization detector (FID). Extracts of samples were interspersed with analytical standards of interest, placed on autosampler with standards at the start, between every 15 samples and the last of the GC sample run. The pesticide residue components were identified by comparing their retention times with those of the standard mixture of the pesticides. Quantification was based on comparison with calibration curves in the concentration range of 0 to $200 \mu \mathrm{g} / \mathrm{L}$. The gas chromatograph's conditions were as follows: injector temperature, $225^{\circ} \mathrm{C}$; injector mode, splitless; oven temperature, programmed from $70^{\circ} \mathrm{C}$, held for 2 min to $180^{\circ} \mathrm{C}$ at a rate of $25^{\circ} \mathrm{C} / \mathrm{min}$, then from $180^{\circ} \mathrm{C}$ to electron capture detector temperature set at $300^{\circ} \mathrm{C}$ at a rate of $10^{\circ} \mathrm{C} / \mathrm{min}$, injector volume, $1.0 \mu \mathrm{L}$. The flame ionization detector working conditions were oven temperature, $60^{\circ} \mathrm{C}$ held for $2 \mathrm{~min}$ to $180^{\circ} \mathrm{C}$ at a rate of $35^{\circ} \mathrm{C} / \mathrm{min}$, then increased to $270^{\circ} \mathrm{C}$ at a rate of $2^{\circ} \mathrm{C} / \mathrm{min}$, and finally increased to $300^{\circ} \mathrm{C}$ at a rate of $5^{\circ} \mathrm{C} / \mathrm{min}$ and held for 10 minutes. The injector mode was splitless and the injection volume $2 \mu \mathrm{L}[15,16]$.

\subsection{Quality Control/Quality Assurance}

Quality control and quality assurance as prescribed by the CODEX Alimentarus Committee were incorporated in the analytical scheme. Quality assurance measures applied in the laboratory included rigorous contamination control procedures (strict washing and cleaning proce- dures), monitoring of blank levels of solvents, equipment and other materials, analysis of procedural blanks, re- covery of spiked standards, monitoring of detector re- sponse and linearity. During extraction, blanks and du- plicates were included in the analysis and re-calibration standards run frequently to check the integrity of the calibration curve. Aliquot (100 ml) of each solvent was concentrated to $2 \mathrm{ml}$ and analyzed to check the contami- nation from the reagents [17]. Percentage recoveries in spiked samples were $68.5 \%-102 \%$, hence the results of the study were not corrected for recoveries since all were within the normal acceptable range of $65 \%-120 \%[17,18]$.

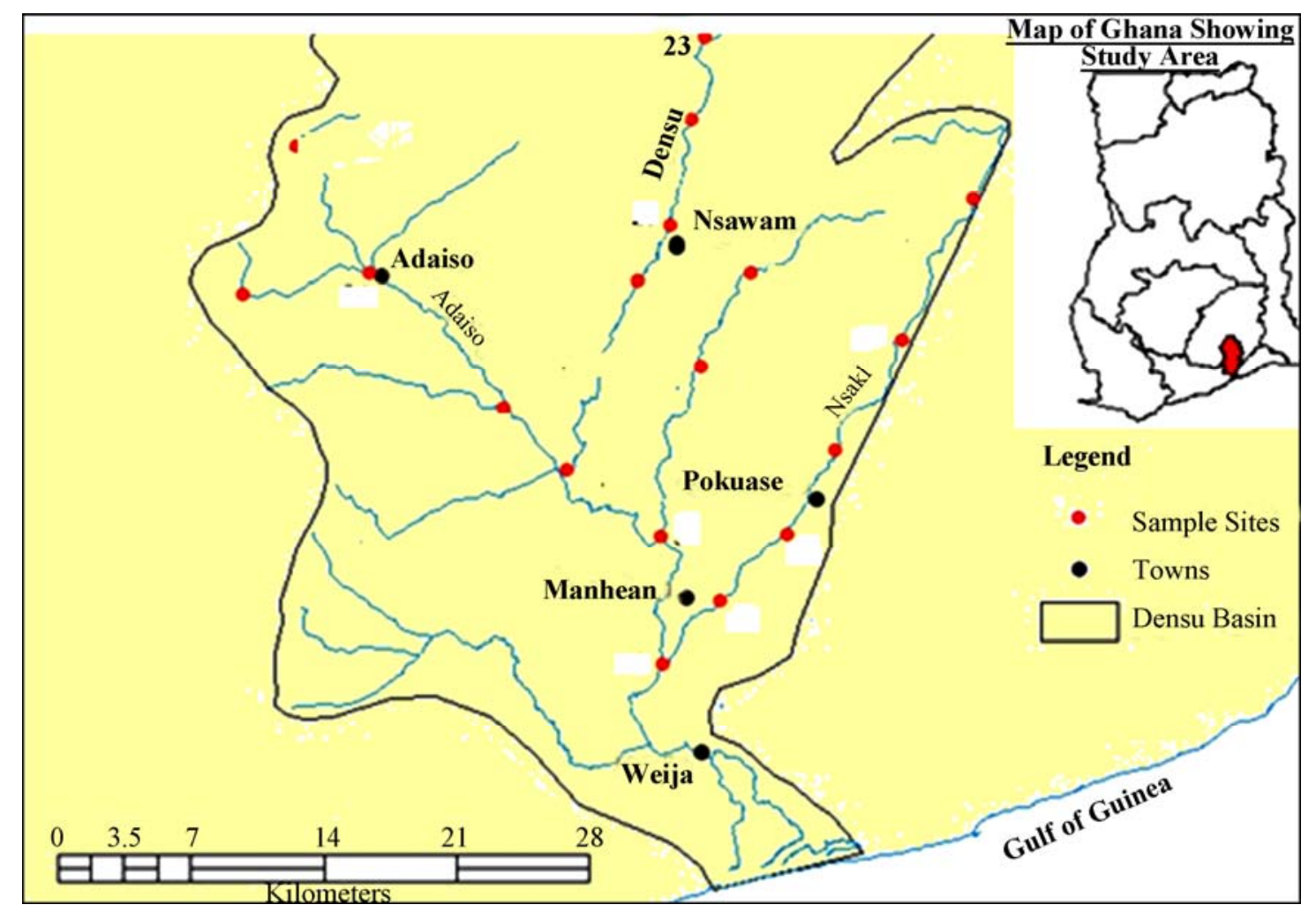

Figure 1. Map of study area. 


\subsection{Health Risk Estimation}

To assess the risk of pesticide on consumers, the guidelines for potential risk assessment drawn up by the US EPA were followed [19]. To evaluate the chronic risk posed by pesticide exposures a reference dose (RfD) is commonly used. This is the level at or below which daily aggregate exposure over a lifetime will pose no appreciable risk to human health. The Reference Dose (RfD) is derived from the "no observable adverse effect levels" (NOAEL) and it is reference point from which potential health effects of a chemical at other doses may be estimated. An aggregate daily exposure to a pesticide residue at or below the RfD is generally considered acceptable by the USEPA, [7,20,21].

Health risk estimates in this study were calculated based on an integration of pesticide analysis data and the consumption rate of fish in Ghana. The following assumptions were adapted from the U.S Environmental Protection Agency's guidelines [19,21]:

1) Hypothetical body weight of $10 \mathrm{~kg}$ for children $(0$ $1 \mathrm{yrs}), 30 \mathrm{~kg}$ for children $(1-11 \mathrm{yrs})$ and $70 \mathrm{~kg}$ for adults.

2) Maximum absorption rate of $100 \%$ and a bioavailability rate of $100 \%$.

3) Food (fish) consumption rate in Ghana is 0.080 $\mathrm{kg} /$ day [22].
Consumption of contaminants in food was calculated based on its concentration in the food and on an estimate of the food consumption rates. Hence for each type of exposure, the lifetime exposure dose $(\mathrm{mg} / \mathrm{kg} /$ day $)$ was obtained by multiplying the residual pesticide concentration $(\mathrm{mg} / \mathrm{kg})$ in the food of interest by the food consumption rate in the country (liter/day or $\mathrm{kg} /$ day) and dividing the product by the body weight $(\mathrm{kg})[4,23]$. The hazard indices for children and adults were estimated as ratios between estimated pesticide exposure doses and the reference doses (RfD). Pesticide residue data from fish samples (Table 1) were used for the health risk assessment. It is important to note that the data used represent the maximum concentrations of pesticide residues in fish samples. Because of the need for conservative approach in dealing with risk assessment of multiple chemical compounds, it was more appropriate to consider the maximum levels of specific detected pesticides instead of their mean concentrations [4]. Moreover, an aggregate daily exposure to a pesticide residue at or below the RfD ia generally considered acceptable by the EPA $(20,21)$ which are considered to be safe levels of exposure over the lifetime.

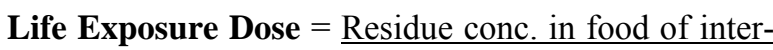
est $X$ food consumption rate Body weight.

Hazard index $=$ Estimated dose/reference dose.

Table 1. Detection frequency and pesticide and metabolite residue concentrations (fresh weight basis) in pooled whole body homogenized fish samples. $(\mathrm{N}=\mathbf{2 0})$.

\begin{tabular}{lcccc}
\hline & Substance & Positive detection & & Concentration $\left(\mu \mathrm{g} \cdot \mathrm{kg}^{-1}\right)$ \\
\cline { 2 - 5 } & $(\%$ of samples $)$ & Min & max & mean \\
\hline$\gamma$-HCH & 75 & 0.10 & 17.65 & 4.94 \\
$\delta$-HCH & 65 & 0.20 & 17.60 & 3.12 \\
heptachlor & 80 & 1.30 & 21.50 & 5.49 \\
aldrin & 50 & 0.10 & 2.90 & 0.65 \\
$\gamma$-chlordane & 70 & 0.25 & 10.15 & 3.02 \\
$\alpha$-endosulfan & 60 & 0.15 & 16.50 & 3.56 \\
p'p'-DDE & 50 & 0.10 & 30.90 & 7.99 \\
dieldrin & 65 & 0.15 & 9.90 & 3.01 \\
endrin & 40 & 0.10 & 6.95 & 2.19 \\
p'p'-DDT & 55 & 0.10 & 12.50 & 4.01 \\
endrin aldehyde & 40 & 0.10 & 1.55 & 0.51 \\
endosulfan Sulphate & 25 & 0.10 & 10.85 & 3.80 \\
endrin ketone & 50 & 0.10 & 6.70 & 2.59 \\
methoxychlor & 60 & 0.10 & 12.60 & 2.27 \\
\hline
\end{tabular}

$\mathrm{N}=$ number of samples 


\section{Results and Discussion}

\subsection{Field Survey}

\subsubsection{Availability of Pesticides}

Most farmers interviewed in the study area derive over $85 \%$ of their income from farming. Pesticides and other agrochemical sources were found to be within reach of farmers. About $80 \%$ of farmers got their agrochemicals within few kilometers from their home while a few of them $(20 \%)$ get their supplies from relatives in the cities. The primary source of agrochemicals in the study area was agrochemical shops (64\%), followed by general shops (14\%) with Cooperative societies representing $12 \%$ of their source of supply and $10 \%$ from relatives (Figure 2).

Most farmers stored agrochemicals in multipurpose storage structures together with food containers and farm implements. The type and amount of pesticides used in different crops depended on the pest population and their potential damages to the crop as well as farmers' perception regarding pest management practices. Most of the farmers $(78 \%)$ apply pesticides in mixtures. There were combinations of up to three pesticides in a single tank mixture. Farmers did not have specific instructions either from the label or from extension officers regarding these tank mixtures. They reported that tank mixing was favourable because it saves time, labour and cost since more than one pesticide could be applied in a single spray.

\subsubsection{Farmers' Knowledge and Attitudes Regarding Safe Use of Agrochemicals, Toxicity Awareness and Symptoms}

Results of the field survey regarding safe use of agrochemicals especially pesticides, toxicity awareness and symptoms among farmers in the study area (Figure 1) indicated that about $84 \%$ of farmers have ever used agrochemicals, $92 \%$ do not wear gloves while $98 \%$ do not

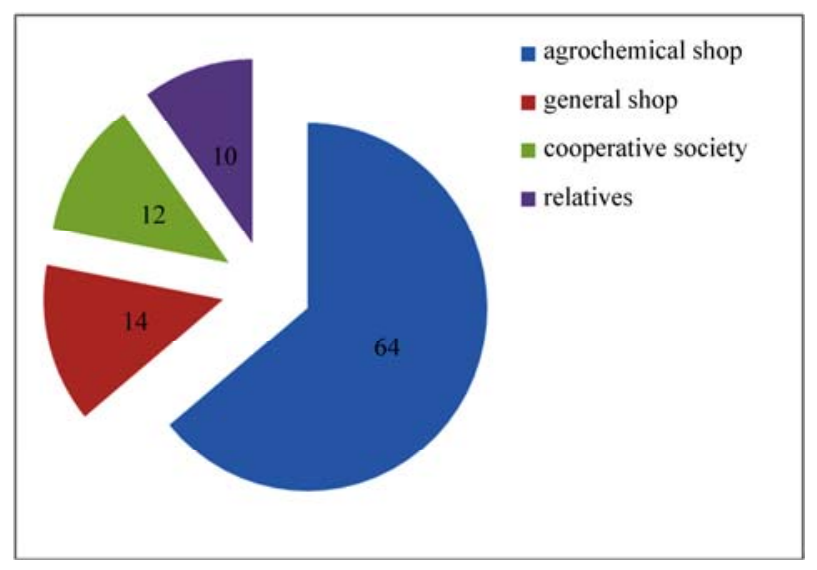

Figure 2. Source of agrochemicals in the Densu River basin. wear eye glasses or goggles when mixing or applying agrochemicals with most of the farmers ( $80 \%)$ wearing long cloths and shoes when applying the chemicals.

Among the respondents, $60 \%$ reported that they have ever eaten food or drank water and $28 \%$ smoked when mixing or applying pesticides. Most farmers $(83 \%)$ had received no training on pesticide and other agrochemical use from the Ministry of Food and Agriculture or any other organization. Farmers are generally less aware of the potentially adverse impacts of pesticide deposition on the environment; nonetheless, they are well aware of the adverse effects of pesticides on human health $(68 \%)$.

About two-third (73\%) of the interviewees had ever experienced various symptoms of pesticide poisoning. Among the clinical symptoms of pesticide poisoning which they reported were nausea, headaches, blurred vision, dizziness, diarrhoea, tingling or burning of skin, abdominal pains, sweating, hypertension and eye irritation. While most farmers believe in the slogan "the more pesticides the better" (76\%), only a minority recognize the need to apply a balanced dosage to their crops (38\%). Furthermore, farmers prefer to spray their crops after noticing insects or weeds in the field and generally refrain from preventive spraying, particularly in the more remote villages. Farmers sometimes mix active ingredients in ways not recommended by the manufacturers (64\%). The number of farmers that adhere to the usage instructions provided on the agrochemical packaging is considerably lower than expected (only $12 \%$ of the total number of farmers interviewed).

The data obtained from the survey indicated that a very high proportion of farmers are at high risk of pesticide poisoning from occupational exposure (Figure 3). Survey analysis indicated that more than $90 \%$ of farmers do not wear protective devices nor apply safety measures during pesticide mixing and application. Pesticide exposure may be exacerbated by the fact that a good proportion of these agricultural workers eat, drink and or smoke during pesticide application. As a result of pesticide exposure, about $73 \%$ of farmers experience various kinds of discomfort including abdominal cramps, excessive salivation, nausea, confusion, eye irritation etc. Several pesticides (organochlorines, organophosphates, carbamate) have been linked to severe human health conditions including neurological damage, hypertension, cardiovascular diseases and skin disorders [5,16]. Some pesticides have been found to cause infertility, sterility and birth defects; others have been linked to allergies, hematologic disorders, mutagenicity and cancer $[2,4,8]$. It is therefore not surprising that a good proportion of the farmers interviewed reported that over the past ten years they had suffered severe health problems including fever, skin irritation, skin diseases, respiratory problems, head- 
ache, abdominal pain, diarrhoea and asthma since they had used most of these pesticides.

Farmers apply agrochemicals without adequate personal protection and in an unsafe manner; moreover, even if they have sufficient income to take protective measures, it is made a matter of lower priority compared to funeral expenses, child education, litigation etc. In addition, labourers are also hired for agrochemical application without providing them with the necessary protective clothing. Shirt and trousers, for example, are frequently worn for extensive periods of time after being contaminated. That seems almost inconceivable as most farmers are aware of the negative effects of pesticides on their health. One reason for not wearing protective clothing, even if it were available, is that the tropical climate makes the wearing of full protective gear impractical because of the potential for body heat stress.

Studies conducted by the International Labour Organization (ILO) suggest that pesticide misuse causes $14 \%$ of occupational injuries in agriculture and, in some countries, as much as $10 \%$ of fatalities [24]. Other contributory factors may include lack of capacity (manpower and financial resources) to advice on and enforce national laws, approved codes of conduct. Lack of washing facilities to shower after spraying and for regular washing of clothes; clothes may be washed in sources of drinking water. Reuse of containers for food and drink storage as well as no facilities for safe disposal. In Ghana, regulation and management of the production, trade and use of agrochemicals is inadequate while there is no access to standards and regulations enforced in importing countries. Poor information, complex label instructions in foreign languages, poor literacy and lack of training in application procedures or hazard awareness, combining different products, applying on crops for which a product is not intended may all contribute to the misuse of pesticides by farmers.

The tank mixture of pesticides observed in this study indicates that farmers lack basic knowledge in pesticide application. Usually labeled instructions do not cover mixtures of three or more pesticides and give no information on the compatibility of inert ingredients. It has been observed that there was an interaction between fungicides, insecticides and water mineral content that influenced the efficacy of individual pesticide against fungal pathogens and insect mortality and some tank mixtures induced phytotoxicity on tomato [25]. Mixtures of insecticides generally result in the simultaneous development of resistance strains [26]. Farmers interviewed did not consider that unspecified tank mixing of pesticides could be less effective and cause adverse effects to their health or the environment; instead, the tank mixing was carried out to save time, labour cost and with anticipation of high efficacy in pests and diseases control. The tank mixtures observed in this study indicated that they were purely on individual thinking and feelings as well as advice from some retailers and not on label instructtions or advice from extension workers.

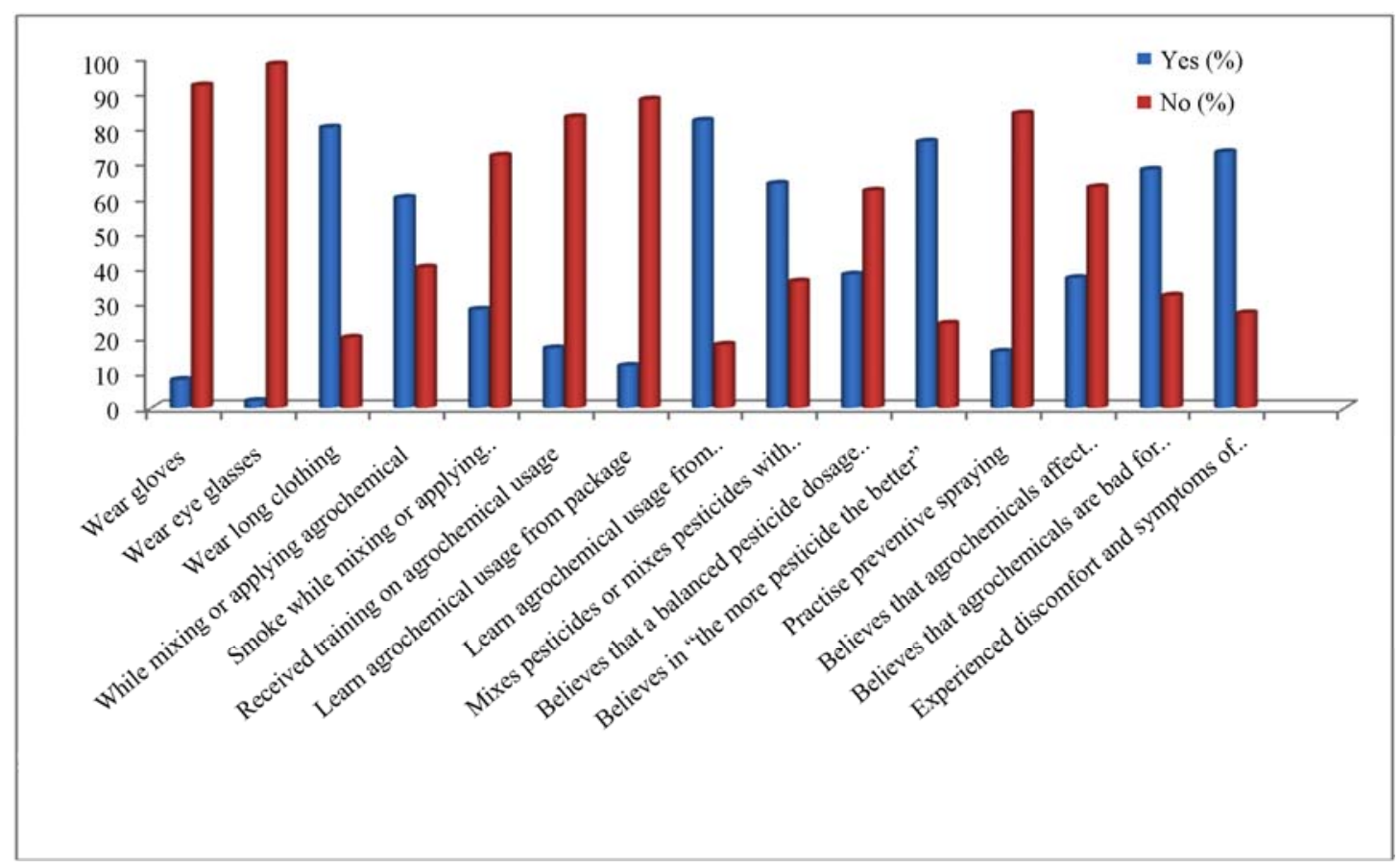

Figure 3. Agrochemical usage and impacts, toxicity awareness and symptoms among farmers in Densu River Basin. 
The preventive measures that farmers were not practicing as compared to curative application that requires application after observing pest problem may probably be due to lack of extension services that could offer appropriate advice. The trend of pesticide use by farmers over the years was probably based on farmers' knowledge on agrochemical application in relation to effecttiveness of agrochemicals, pests, farm size, prices and weather condition. The risk of long-term effects of the pesticides that were being used in the study area is high especially due to exposure to carcinogens, possible carcinogens and suspected endocrine disruptors.

\subsection{Health Risk Estimates}

Table 1 represents the pesticide residue data from the fish samples analyzed while Table 2 represents the estimated dose values and health hazards associated with pesticide residues in fish from the Densu Basin. Hazard indices were computed for children between the ages of 0 - 1years, 1 - 11years and adults for aldrin, methoxychlor, $\gamma$-chlordane, endrin aldehyde, endrin ketone, endrin, p'p'- DDT, $\gamma$-HCH, DDE, $\delta$-HCH, ,heptachlor, $\alpha$-endosulfan, endosulfan sulphate, and dieldrin.
Data analysis of health risk estimates indicate that aldrin, methoxychlor, $\gamma$-chlordane, endrin aldehyde, endrin ketone, endrin, p'p'-DDT, $\gamma-\mathrm{HCH}, \mathrm{DDE}$ and $\delta-\mathrm{HCH}$ do not pose direct hazard to human health, although present in fish samples. However, heptachlor, $\alpha$-endosulfan, endosulfan sulphate, and dieldrin levels exceeded the reference dose in children between the ages of $0-1$ years, indicating a great potential for systemic toxicity in children who are considered to be the most vulnerable population subgroup. In children between the ages of $0-1$ years, the hazard indices of $2.64,1.720,1.736$ and 0.792 (Table 2) were computed for $\alpha$-endosulfan, heptachlor, endosulfan sulphate and dieldrin respectively and were found to be of health risk to them since the estimated dose exceeded the recommended reference dose.

For children between the ages $1-11$ years, heptachlor, $\alpha$-endosulfan and endosulfan posed health hazard to them since they recorded significant health indices of 0.573 , 0.880 and 0.576 respectively. The estimated dose of heptachlor $(0.057 \mu \mathrm{g} / \mathrm{kg} /$ day $)$ was quite closer to the reference dose of $0.10 \mu \mathrm{g} / \mathrm{kg} /$ day in children between the ages of $1-11$ years resulting in possible health hazard on exposure to fish or fish products from the basin.

Table 2. Estimated dose values and Hazard indices of pesticide exposure in contaminated fish from the Densu River Basin.

\begin{tabular}{|c|c|c|c|c|c|c|c|}
\hline \multirow[b]{2}{*}{ Pesticide } & \multirow[b]{2}{*}{$\begin{array}{c}\text { Reference dose } \\
\mu \mathrm{g} / \mathrm{kg} / \mathrm{day}\end{array}$} & \multicolumn{3}{|c|}{ Estimated dose ( $\mu \mathrm{g} / \mathrm{kg} /$ day) } & \multicolumn{3}{|c|}{ Hazard index } \\
\hline & & $0-1 y r s$ & $1-11 y r s$ & Adult & $0-1 y r$ & $1-11 y r$ & Adult \\
\hline$\gamma-\mathrm{HCH}$ & 0.30 & 0.141 & 0.047 & 0.020 & 0.471 & 0.157 & 0.067 \\
\hline$\delta-\mathrm{HCH}$ & 3.00 & 0.141 & 0.047 & 0.020 & 0.047 & 0.016 & 0.007 \\
\hline heptachlor & 0.10 & 0.172 & 0.057 & 0.025 & 1.720 & 0.573 & 0.246 \\
\hline aldrin & 0.10 & 0.023 & 0.008 & 0.003 & 0.232 & 0.077 & 0.033 \\
\hline$\gamma$-chlordane & 0.50 & 0.081 & 0.027 & 0.012 & 0.1624 & 0.054 & 0.023 \\
\hline$\alpha$-endosulfan & 0.05 & 0.132 & 0.044 & 0.019 & 2.64 & 0.880 & 0.377 \\
\hline p'p'-DDE & 0.50 & 0.247 & 0.082 & 0.035 & 0.4944 & 0.165 & 0.071 \\
\hline dieldrin & 0.10 & 0.079 & 0.026 & 0.011 & 0.792 & 0.264 & 0.113 \\
\hline endrin & 0.20 & 0.056 & 0.019 & 0.008 & 0.278 & 0.093 & 0.040 \\
\hline p'p'-DDT & 0.50 & 0.100 & 0.033 & 0.014 & 0.2 & 0.067 & 0.029 \\
\hline endrin aldehyde & 0.20 & 0.012 & 0.004 & 0.002 & 0.062 & 0.021 & 0.009 \\
\hline endosulfan Sulphate & 0.05 & 0.087 & 0.029 & 0.012 & 1.736 & 0.579 & 0.248 \\
\hline endrin ketone & 0.20 & 0.054 & 0.018 & 0.008 & 0.268 & 0.089 & 0.038 \\
\hline methoxychlor & 5.00 & 0.1018 & 0.034 & 0.014 & 0.020 & 0.007 & 0.003 \\
\hline
\end{tabular}


Although residue levels of these pesticides are below the maximum permissible intake of Codex Committee on pesticides residues [1], there was no zero risk because there were pesticides present in fish. Most of the detected compounds are generally persistent, volatile, lipophilic and bioaccumulative both in the environment and at each trophic level of the food chain. Contaminants can thus reach high concentrations through biomagnifications in the tissues of predators including humans, which are high on the food chain [27]. They are prone to long range transport and deposition and can result in adverse environmental and human health effects at locations near and far from the source.

\section{Conclusions}

It is clear from the results of the study that the farming communities in the Densu Basin of Ghana do not follow appropriate safety precautions with regard to agrochemical application. Substantial amounts of agrochemicals especially pesticides are inappropriately used by these farmers leading to several clinicopathological conditions including nausea, vomiting, blurred vision, abdominal cramps, dizzineaa, diarrhea and headache. The estimated dose for aldrin, methoxychlor, $\gamma$-chlordane, endrin aldehyde, endrin ketone, endrin, DDE, p'p'-DDT, $\gamma-\mathrm{HCH}$ and $\delta-\mathrm{HCH}$ do not pose a direct hazard to human health, although present in fish samples since the values were lower than toxic thresholds as well as reference dose and may indicate minimum risk to human. However, heptachlor, $\alpha$-endosulfan, endosulfan sulphate, and dieldrin levels exceeded the reference dose, indicating a great potential for systemic toxicity in children who are considered to be the most vulnerable population subgroup. Although residue levels of these pesticides are below the maximum permissible intake, there was no zero risk because there were pesticides present in fish and other matrices. Human exposure during pesticide application is exacerbated by water, food and environmental contamination and there exists a potential risk for systemic and carcinogenic health effects associated with agrochemical usage in the Densu Basin.

\section{REFERENCES}

[1] F. Sun, S. S. Wong, G. C. Li and S. N. Chen, "A Preliminary Assessment of Consumer's Exposure to Pesticide Residues in Fisheries Products," Chemosphere, Vol. 62, No. 4, 2006, pp. 674-680. doi:10.1016/j.chemosphere.2005.04.112

[2] F. O. Mensah, F. A. Yeboah and M. Akman, "Survey of the Effect of Aerosol Pesticide Usage on the Health of Farmers in the Akomadan and Afrancho Farming Community," Journal of Ghana Science Association, Vol. 6, No. 2, 2004, pp. 44-48.

[3] R. A. Fenske, J. C. Kissel, C. Lu, D. A. Kalman, N. J.
Simcox, E. H. Allen and M. C. Keifer, "Biologically Based Pesticide Dose Estimates for Children in Agricultural Community," Environmental Health perspectives, Vol. 108, No. 6, 2000, pp. 515-520. doi:10.1289/ehp.00108515

[4] B. P. Tchounwou, B. A. Ashour, D. A. Ragheb and A. A. Romeh, "Health Risk Assessment of Pesticide Usage in Menia El-Kamh Province of Sharkia Governorate in Egypt," International Journal of Molecular Sciences, Vol. 3, No. 10, 2002, pp. 1082-1094. doi: $10.3390 / 13101082$

[5] G. M. Calvert, W. T. Sanderson, M. Barnet, J. M. Blondell and L. N. Melher, "Surveillence of Pesticide-Related Illness and Injury in Humans," In: Handbook of Pesticide Toxicology, $2^{\text {nd }}$ Edition, Academic Press, New York, 2001.

[6] K. D. Whitney, F. J. Seildler and T. A. Stotkin, "Developmental Neurotoxicity of Chlorpyrifos: Cellular Mechanisms," Toxicology and Applied Pharmacology, Vol. 134, No. 1, 1995, pp. 53-62. doi:10.1006/taap.1995.1168

[7] D. J. Snelder, M. D. Maasipiquena and G. R. de Snoo, "Risk Assessment of Pesticide Usage by Smallholder Farmers in the Cagayan Valley (Philippines)," Crop Protection, Vol. 27, No. 3-5, 2008, pp. 747-762. doi:10.1016/j.cropro.2007.10.011

[8] J. W. Ntow, "Pesticide Residues in Volta Lake, Ghana," Lakes and Reservoirs: Research and Management, Vol. 10, No. 4, 2005, pp. 243-248. doi:10.1111/j.1440-1770.2005.00278.x

[9] F. A. Yeboah, F. O. Mensah and A. K. Afreh, "The Probable Toxic Effects of Aerosol Pesticides on Hepatic Function among Farmers at Akomadan/Afrancho Traditional Area of Ghana," Journal of Ghana Science Association, Vol. 6, No. 2, 2004, pp. 39-43.

[10] E. Adetola, J. K. Ataki, E. Atidepe, D. K. Osei and A. B. Akosa, "Pesticide Poisoning - a Nine Year Study (1989 - 1997)," Department of Pathology, University of Ghana Medical School and Ghana Standards Board Accra, 1999.

[11] E. E. K. Clarke, L. S. Levy, A. Spurgeon and I. A. Calvert, "The Problems Associated with Pesticide Use by Irrigation Workers in Ghana," Occupational Medicine, Vol. 47, No. 5, 1997, pp. 301-308. doi:10.1093/occmed/47.5.301

[12] P. O. Yeboah, G. M. S. Klufio, G. A. Dixon and A. Youdeowe, "TCDC Oriented Subregional Workshop on Pesticides Management Report," FAO, 1989, pp. 8-9.

[13] FDA, "Multiresidue Method," Pesticides Analytical Manual, Vol. 1, No. 94-1, 1994, from 2905a (6/92).

[14] M. Akerblom, "Environmental Monitoring of Pesticide Residues. Guidelines for the SADC Region. SADC/ ELMS," Monitoring techniques, Series 3, Lesotho, 1995.

[15] J. L. Zhou, H. Hong, Z. Zhang, K. Maskaoui and W. Chen, "Multi-Phase Distribution of Organic Micropollutants in Xiamen Harbour, China," Water Research, Vol. 34, No. 7, 2000, pp. 2132-2150. doi:10.1016/S0043-1354(99)00360-7 
[16] USEPA, "Test Methods for Evaluating Solid Wastes SW-846," Volume IA-Laboratory Manual: Physical and Chemical Methods, US EPA Office of Solid Waste and Emergency Response, Washington D.C., 1994.

[17] FAO/WHO, "Codex Maximum Residue Limits for Pesticides," FAO, Rome, 2007.

[18] A. Hill, "Quality Control Procedures for Pesticide Residues Guidelines for Residues Monitoring in the European Union," $2^{\text {nd }}$ Edition Document No. SANCO/3103/2000, European Commission, 2000.

[19] USEPA, "Guidelines for Ecological Risk Assessment," Washington, US EPA, Report No. EPA/630/ R-95/002F, 1998.

[20] USEPA, "Lamda-Cyahalothrin Pesticide Tolerances, Final Rule," Federal Register (Rules and Regulations), Vol. 67, No. 188, 2002a, pp. 60902-60915.

[21] USEPA, "Integrated Risk Information System," USEPA, Office of Health and Environmental Assessment. Washington D.C., 1996.
[22] FAO. FAO fisheries and Aquaculture, Ghana, 2001. www.fao.org/fisheries/country sector/F1-cp

[23] USEPA, "Exposure Assessment Handbook," USEPA, Office of Health and Environmental Assessment, Washington D.C., 1989.

[24] Codex, "Codex Classification of Food and Animal Feed (Codex Alimentarius) Pesticide Residues in Food," Rome, 2005.

[25] Z. K. Smit, D. Indjic, S. Belic and M. Miloradov, "Effect of Water Quality on Physical Properties and Biological Activity of Tank Mix Insecticide-Fungicide Spray," Proceedings of the Second Balkan Symposium on Vegetables and Potatoes, International Society Horticultural Science, Leuven, Belgium, Vol. 579, 2002, pp. 551-556.

[26] A. V. F. Ngowia, T. J. Mbisea, A. S. M. Ijania, L. Londonb and O. C. Ajayic, "Smallholder Vegetable Farmers in Northern Tanzania: Pesticides Use Practices, Perceptions, Cost and Health Effects," Crop Protection, Vol. 26, No. 11, 2007, pp. 1617-1624. doi:10.1016/j.cropro.2007.01.008 